\title{
Physicochemical properties and sensory evaluation of yogurt nutritionally enriched with papaya
}

\author{
${ }^{1}$ Othman, N., ${ }^{2}$ Hazren, A. Hamid and ${ }^{1,}$ " Suleiman, N. \\ ${ }^{1}$ Department of Food Technology, Faculty of Food Science and Technology, Universiti Putra Malaysia \\ 43400 UPM Serdang, Selangor, Malaysia \\ ${ }^{2}$ Department of Civil Engineering, Faculty of Engineering Technology, University of Tun Hussein Onn, \\ 84600 Panchor, Johor, Malaysia
}

\begin{abstract}
Article history:
Received: 14 May 2019

Received in revised form: 11

June 2019

Accepted: 12 June 2019

Available Online: 27 June

2019
\end{abstract}

Keywords:

Papaya,

Yogurt,

Nutritional enrichment,

Sensory analysis

DOI:

https://doi.org/10.26656/fr.2017.3(6).199

\begin{abstract}
Yogurts are one of the most consumed dairy products, especially in Western and Middle East countries. Papaya is an abundant tropical fruit that contains much higher levels of vitamins and minerals than other tropical fruits. The aim of this work was to develop a protein-rich papaya-flavored yogurt as an inexpensive, nutritionally balanced, healthy snack. The influenced of adding papaya puree at different percentages $(5,10,15,20,25 \%)$ on physicochemical and rheological have been explored. This work also investigated consumer preferences in relation to these yogurts, using ratings made by thirty Malaysian participants on a five-point hedonic scale. The addition of papaya to the pure yogurt (up to $25 \%$ by weight) increased the product's crude protein content by up to $46 \%$ and reduced its fat content by up to $27 \%$. Nevertheless, the addition of $20 \%$ of papaya puree to the yogurt was the most preferred according to sensory evaluation. On most of the attributes tested, participants gave higher ratings for the yogurt nutritionally enriched with papaya than for the pure yogurt. The enrichment of natural yogurt with papaya puree showed to be effective with higher nutritional characteristics.
\end{abstract}

\section{Introduction}

The recent increase in the number of nutritious milk products offered by the global dairy industry is remarkable. This is partly due to the growing consumer interest in healthy eating. Yogurt is commonly associated with beneficial effects on human health, and hence there has been an increase in the consumption of yogurt globally (Barbosa et al., 2017). Yogurt/fermented milk is a semi-solid acidified dairy product that was first introduced at the end of the $19^{\text {th }}$ century; the traditional production process (milk fermentation) offered a means to preserve milk before the advent of heat treatment (Chandan et al., 2006). Today, in the production of most yogurt, pasteurized milk is fermented with a starter culture containing lactic acid bacteria such as Lactobacillus bulgaricus and Streptococcus thermophilus (Shiby and Mishra, 2013; Kumar Dutta Roy, 2015). These bacteria convert lactose to lactic acid through fermentation, and hence are responsible for the development of yogurt's characteristic body and texture, contribute to the overall flavor, and enhance preservation (Hati et al., 2013).

Yogurt contains high levels of calcium, magnesium, phosphorus, and zinc (De La Fuente et al., 2003).
Moreover, its low lactose content (relative to milk) makes it easily digestible (Kumar Dutta Roy, 2015). Yogurt improves gastrointestinal health and is, for instance, an effective remedy for diarrhea (Kamruzzaman et al., 2002), lower cholesterol levels (Gilliland, 1989) and to prevent the development of tumors (Marshall, 1993). In addition, yogurt also has high antimicrobial activity (Mirzaei et al., 2018). The exact composition of the raw milk, the strains of bacteria used, and the manufacturing process are the main factors that affect the physical properties of yogurt, such as its color, flavor, aroma, and texture (Kumar and Mishra, 2004).

Nutritional value is readily added to yogurt by combining it with nutritious fruits, nuts or even vegetables. Typically, fruits such as strawberry, peach, apricot, mango, banana, or blueberry are added. Fruit yogurts are popular with consumers because of their flavor and other sensory properties (e.g. texture) but also their nutritional value (Čakmakči et al., 2012). The FAO and the WHO have recommended that yogurt products contain $5-15 \%$ fruit by weight (Farahat and El-Batawy, 2013). However, the development of high-protein yogurt is a worthwhile challenge (Klunklin and Savage, 2018). 
When developing a new product it is generally important to use locally sourced ingredients, as they are more likely to be appreciated (principally in terms of taste) by consumers (Klunklin and Savage, 2018). Papaya is an economically important fruit that is extensively cultivated and marketed worldwide. Malaysia is one of the major papaya-producing countries in the world and the second largest exporter, after Mexico (Medina et al., 2002). It is a nutritious fruit and it has a pleasant taste and mouthfeel and is beneficial to health. Recently, researchers have become interested in "functional" foods - foods of high nutritional value that promote good health (Klunklin and Savage, 2018). Raw papaya is good for health because it is very low in saturated fat, cholesterol, and sodium. It is also a good source of carotenoids, vitamin $\mathrm{C}$, thiamin, riboflavin, niacin, vitamin B-6, and vitamin K (Bari et al., 2006; Adetuyi et al., 2008). Ripe papaya is commonly consumed as a dessert or processed into jam, puree or wine, while unripe papaya can be used as a salad ingredient or cooked as a vegetable (Ahmed et al., 2002). Papaya is also a traditional medicine, used in the treatment of various diseases (Boshra and Tajul, 2013).

The incorporation of fruits such as papaya into a yogurt will enhance its nutritional value. Nonetheless, an understanding of the underlying needs, values, and insights of the consumer is the key to product optimization, especially for functional foods. Grainy texture, a flavor that is too tart, sloppiness and syneresis are common problems in the manufacture of yogurt. The effects of different concentrations of papaya in a yogurt product on its physicochemical properties and sensory evaluation remain largely unexplored. Therefore, the present work aimed to develop a papaya yogurt as a nutritious and healthy food that meets the approval of consumers.

\section{Materials and methods}

\subsection{Materials}

Papaya was obtained from a local market, in Kampung Berjaya, Kedah, Malaysia. Its ripeness was assessed using the criteria suggested by Sapii and Muda (2005). Fresh milk, skimmed milk, sweetener, xantham gum, and yogurt starter were acquired from a local supplier in Serdang, Selangor, Malaysia. All the ingredients used in the preparation of the study products were checked for shelf-life and product quality certification.

\subsection{Nutritional enrichment of the yogurt}

\subsubsection{Preparation of papaya puree}

The fresh papaya was washed in tap water to remove any dirt on the skin, manually peeled with a knife, and then blended using a blender. The prepared fruit was cooked in a pot at $95^{\circ} \mathrm{C}$ for 15 mins and mixed with sugar (the added sugar was $10 \%$ of the weight of the raw papaya). After cooking, the papaya puree was allowed to cool to room temperature and was then refrigerated at $4^{\circ}$ C.

\subsubsection{Production of yogurt}

Skimmed milk powder $(6 \%$ of the final mix, by weight), sugar $(6 \%)$, and xanthan gum $(0.2 \%)$ were added to fresh whole milk. This mix was heated using the double boiler method and stirred frequently to avoid burning until the milk reached $82^{\circ} \mathrm{C}$ (Katz, 2016). This heating produces a thicker yogurt. The mix was allowed to cool to $42-43^{\circ} \mathrm{C}$ (Roy et al., 2015). The cooled milk mix then underwent the inoculation process. It was inoculated with a starter culture $(0.5 \%$ of the milk mix, by weight) containing Lactobacillus delbrueckii subsp. bulgaricus, Lactobacillus casei, Lactobacillus acidophilus, and Bifidobacterium longum (Yogourmet, Canada). The inoculated milk was kept in an incubator at $37^{\circ} \mathrm{C}$ for $8-12 \mathrm{hrs}$ until curd formation was complete (Roy et al., 2015). After this fermentation process, all the samples were stored at $4^{\circ} \mathrm{C}$. Five yogurt products with different concentrations (by weight) of the papaya puree were prepared: $0 \%$ (pure yogurt with no papaya), $10 \%$, $15 \%, 20 \%$, and $25 \%$ papaya, henceforth denoted $\mathrm{P} 0$, $\mathrm{P} 10, \mathrm{P} 15, \mathrm{P} 20$, and P25 respectively. The products were otherwise identical.

\subsection{Physicochemical analysis}

\subsection{1 $\mathrm{pH}$ value}

This was measured using a Seven Easy Mettler Toledo $\mathrm{pH}$ meter that had been calibrated with a buffer solution at pH 7.0 and 4.0 (Mettler Toledo, Switzerland).

\subsubsection{Composition}

Moisture, ash, crude protein, and crude fat content were determined according to the method recommended by the Association of Official Analytical Chemists (AOAC) (AOAC, 1995). Moisture content was determined using the oven drying method (AOAC Method 977.11). Ash content was obtained by drying the sample (AOAC Method 923.03). Crude protein was determined using Kjeldahl's method (AOAC Method 955.04). Crude fat was obtained using the Soxhlet method (AOAC Method 960.39).

\subsubsection{Carbohydrate content}

The carbohydrate content was estimated by the formula given by BeMiller and Low (1998) as follow:

[Carbohydrate $(\%)=100 \%-\%$ (moisture + protein + fat + ash)] 
The Brix value (sugar content) of the papayaflavored yogurt was determined by using a refractometer. The sample plate was cleaned and dried. A few drops of the sample were placed on the plate, which was then closed. The refractometer was held up to a natural light source and the reading was recorded.

\subsubsection{Color}

An Ultrascan Hunter Lab Spectrocolourimetric (Hunter Associate Laboratory Inc., Reston, USA) was used to determine the color and color intensity of the papaya-flavored yogurt. The chromatographic data were collected and processed (using a personal computer running Easy Match QC Data System Software) as $L^{*}$, $a^{*}$, and $b^{*}$ values, where $L=$ lightness $(0=$ black, $100=$ white), $-a=$ greenness, $+a=$ redness, and $-b=$ blueness, $+b=$ yellowness. The samples were put in a container that was placed over the spectrocolorimeter port, enclosed within a blackened container to remove ambient light.

\subsection{Viscosity}

The rheological of papaya-flavored yogurt in term of viscosity was determined using Dynamic Controlled Stress Rheometer (Anton Paar, US).

\subsection{Sensory evaluation}

Sensory evaluations of the papaya-flavored yogurts were carried out by thirty participants, recruited from the students and staff at the Sensory Laboratory, Faculty of Food Science and Technology, Universiti Putra Malaysia (UPM). The participants rated their degree of liking of the products on a five-point hedonic scale $(1=$ unsatisfactory; 3 = good; and $5=$ excellent). The participants were randomly allocated different products using simple random sampling. The sensory parameters of appearance, color, texture, aroma, papaya flavoring, sweetness, and overall quality were rated.

\subsection{Statistical analysis}

All the measurements were repeated three times for each sample and average values were calculated. All the data obtained were evaluated as means with standard deviations. One-way ANOVA (calculated using Minitab 16) was used to assess the statistical significance of differences. Probability values were considered significant at $\mathrm{p}<0.05$.

\section{Results and discussion}

\subsection{Composition of the papaya-enriched yogurts}

Papaya-enriched yogurt was analyzed for selected physicochemical properties. Table 1 tabulates the compositions of the yogurts with different concentrations of papaya puree. The initial $\mathrm{pH}$ of the fresh milk was $7.75 \pm 0.02$ and the $\mathrm{pH}$ of the plain yogurt (after incubation at $37^{\circ} \mathrm{C}$ for $8-12 \mathrm{hrs}$ ) was 5.66. The production of lactic acid results in the coagulation of the milk (Guner et al., 2007). According to Roy et al. (2015), lactic acid bacteria have the ability to ferment the sugar (lactose) in milk into lactic acid (Kumar Dutta Roy, 2015), and so yogurt should have a lower $\mathrm{pH}$ than milk. Nevertheless, the $\mathrm{pH}$ of the study yogurt products is increased by the addition of papaya puree. Accordingly, the $\mathrm{pH}$ increases significantly as the percentage of papaya in the yogurts increases, with the highest $\mathrm{pH}$, of 5.82, being recorded for the product with $25 \%$ papaya puree. A similar observation was reported by Amal et al. (2016).

${ }^{\circ}$ Brix is the measurement of the soluble solid in a food product. The sugar content in yogurt is measured in ${ }^{\circ}$ Brix. The papaya yogurts had significantly $(p<0.05)$ higher Brix values than the control yogurt (P0). The papaya puree used in this study had a Brix value of $20.40^{\circ}$. Papaya puree contains several soluble sugars, including glucose and sucrose (Gomez et al., 2002). The initial sugar content of the control yogurt (P0) before the fermentation process was $19^{\circ}$ Brix. During fermentation, the sugar content is reduced (Hoang et al., 2016). However, it can be noticed that the sugar content of the

Table 1. Physicochemical properties of yogurts with different percentages of papaya

\begin{tabular}{lccccc}
\hline Properties & P0 & P10 & P15 & P20 & P25 \\
\hline pH & $5.66 \pm 0.02^{\mathrm{d}}$ & $5.74 \pm 0.02^{\mathrm{c}}$ & $5.78 \pm 0.01^{\mathrm{b}}$ & $5.81 \pm 0.00^{\mathrm{a}, \mathrm{b}}$ & $5.82 \pm 0.01^{\mathrm{a}}$ \\
${ }^{\circ}$ Brix & $7.00 \pm 0.00^{\mathrm{e}}$ & $9.00 \pm 0.00^{\mathrm{d}}$ & $9.47 \pm 0.12^{\mathrm{c}}$ & $10.00 \pm 0.00^{\mathrm{b}}$ & $10.80 \pm 0.35^{\mathrm{a}}$ \\
Moisture content & $88.21 \pm 0.20^{\mathrm{a}}$ & $87.80 \pm 0.05^{\mathrm{b}}$ & $87.52 \pm 0.14^{\mathrm{b}}$ & $87.45 \pm 0.11^{\mathrm{b}}$ & $87.59 \pm 0.10^{\mathrm{b}}$ \\
Ash & $0.48 \pm 0.02^{\mathrm{a}}$ & $0.54 \pm 0.01^{\mathrm{a}}$ & $0.65 \pm 0.05^{\mathrm{a}}$ & $0.66 \pm 0.03^{\mathrm{a}}$ & $0.67 \pm 0.15^{\mathrm{a}}$ \\
Protein & $1.62 \pm 0.07^{\mathrm{c}}$ & $2.10 \pm 0.04^{\mathrm{b}}$ & $2.25 \pm 0.07^{\mathrm{a}, \mathrm{b}}$ & $2.29 \pm 0.07^{\mathrm{a}}$ & $2.37 \pm 0.09^{\mathrm{a}}$ \\
Fat & $1.80 \pm 0.00^{\mathrm{a}}$ & $1.65 \pm 0.07^{\mathrm{a}, \mathrm{b}}$ & $1.65 \pm 0.07^{\mathrm{a}, \mathrm{b}}$ & $1.60 \pm 0.14^{\mathrm{a}, \mathrm{b}}$ & $1.30 \pm 0.14^{\mathrm{b}}$ \\
Carbohydrate & $7.89 \pm 0.00^{\mathrm{e}}$ & $7.91 \pm 0.00^{\mathrm{d}}$ & $7.94 \pm 0.00^{\mathrm{c}}$ & $7.99 \pm 0.00^{\mathrm{b}}$ & $8.07 \pm 0.00^{\mathrm{a}}$ \\
\hline
\end{tabular}

Chemical composition was calculated based on the dry matter. Each value is expressed as mean \pm standard deviation $(\mathrm{n}=3$ ). Different alphabet superscripts in the same row indicate significant differences $(p<0.05)$ according to the Tukey test. 
study products increased with the addition of papaya puree, due to its high sugar content.

Food quality, preservation, and resistance to deterioration are the main issues related to the moisture content of food (Nielsen, 2015). The moisture content of the yogurt products ranged from $87.45 \%$ to $88.21 \%$. The addition of papaya puree to the yogurt significantly reduced its moisture content. A similar observation was reported by Amal et al. (2016). The puree adds solids to the yogurt, and hence decreases its moisture content (Mahmood, 2008). In principle, the texture of the yogurt will be influenced by the moisture content (Amal et al., 2016). For instance, the firmness of the yogurt will increase if the moisture content is low (Amal et al., 2016).

A significant difference was found in the crude protein content of the product when papaya puree was added to the yogurt. The yogurt product with $25 \%$ papaya puree had the highest crude protein content $(2.37 \%)$ and the control product the lowest (1.62\%). This represents an approximately $46 \%$ increase in the crude protein. This shows that the addition of papaya does increase the nutritional value of yogurt. According to the USDA National Nutrient Database, $100 \mathrm{~g}$ of fresh papaya contains $0.47 \mathrm{~g}$ of protein. Amal et al. (2016) reported that the protein content of yogurt increased in proportion with the percentage of fruit.

The ash content represents the total amount of minerals present - such as sodium, potassium, magnesium, calcium, zinc, and iron (Lakshmipathy and Sarada, 2013). The ash content of the papaya yogurts was not significantly different from that of the control yogurt (P0). Papaya pulp has been reported to have lower mineral content than papaya seed (Nwofia et al., 2012). The addition of papaya puree to the yogurt did not significantly affect the mineral content of the yogurt.

The milk quality, fruit variety, and amount of fruit pulp added to the yogurt are the important elements influencing the fat content of a yogurt product. The fat content of the control yogurt (P0) was $1.8 \%$. The addition of papaya puree slightly decreased the fat content, down to $1.30 \%$ in $\mathrm{P} 25$, representing a $27 \%$ decrease. A similar observation was reported by Amal et al. (2016). Roy et al. (2015) also found that the fat content of fruit yogurts decreased gradually with increasing proportions of fruit pulp because the fat content of fruit pulp is lower than that of milk (Kumar Dutta Roy, 2015).

The yogurt enriched with papaya puree had significantly higher carbohydrate content (up to $8.07 \%$ ) than the control sample (7.89\%). This can be attributed to the high glucose and sucrose content of papaya pulp (Gomez et al., 2002). This finding is supported by Amal et al. (2016), who reported that the addition of fruit increased the carbohydrate content of a yogurt (Amal et al., 2016).

\subsection{Viscosity}

Perceived viscosity is very important aspects in determining the quality and acceptance of yogurts. An understanding of the mechanisms and the effect of processing conditions on the yogurt texture may improve the quality of yogurt. From the observations, there were no significant differences between the investigated sample (Table 2). This is might due to the insufficient amount of papaya puree added in the sample. Nevertheless, by adding 20 up to $25 \%$ papaya puree in the yogurt increases the viscosity of papaya-flavored yogurt. Higher solid and fiber content in papaya contributes to the increase of viscosity and improve the textural properties of fruit yogurt (Roy, 2015). This is due to the pectin and fructose in fruit which helps to improve the consistency and viscosity of the yogurt, hence, produced better textural quality than control yogurt.

Table 2. Viscosity parameter of yogurts with different percentages of papaya

\begin{tabular}{cccccc}
\hline Sample & P0 & P10 & P15 & P20 & P25 \\
\hline \multirow{2}{*}{ Viscosity } & $0.01 \pm$ & $0.01 \pm$ & $0.01 \pm$ & $0.02 \pm$ & $0.04 \pm$ \\
& $0.00^{\mathrm{a}}$ & $0.00^{\mathrm{a}}$ & $0.00^{\mathrm{a}}$ & $0.01^{\mathrm{a}}$ & $0.02^{\mathrm{a}}$ \\
\hline
\end{tabular}

Each value is expressed as mean \pm standard deviation $(n=3)$. Different alphabet superscripts in the same row indicate significant differences $(\mathrm{p}<0.05)$ according to the Tukey test.

\subsection{Color evaluation}

Color is the most important cue used by consumers to judge the quality and appearance of food. It is essential to consumer decisions to purchase and to consume a food product. When analyzing the color parameters of the yogurts (Table 3), it was observed that the progressive addition of papaya puree resulted in significant differences $(p<0.05)$ in lightness $\left(L^{*}\right)$. The color analysis shows that sample P20 was brighter than the other samples. The redness and yellowness values of the sample are indicated by $\mathrm{a}^{*}$ and $\mathrm{b}^{*}$ values, respectively. Zuhair et al. (2013) stated that papaya pulp is an orange-red color with a low $\mathrm{L}^{*}$ value, and high a* and $b^{*}$ values. In Table 3 it can be seen that the redness $\left(a^{*}\right)$ and yellowness $\left(b^{*}\right)$ values increased significantly as the percentage of papaya puree increased. The redness and yellowness are attributes of the carotenoids present in papaya (Nwofia et al., 2012).

\subsection{Sensory attributes}

Comparisons of the mean scores for the sensory 
Table 3. Color parameters of yogurts with different percentages of papaya

\begin{tabular}{rcccccc}
\hline Properties & P0 & P10 & P15 & P20 & P25 \\
\hline \multirow{4}{*}{ Color } & $\mathrm{L}^{*}$ & $47.47 \pm 0.28^{\mathrm{c}}$ & $48.56 \pm 0.15^{\mathrm{c}}$ & $54.38 \pm 1.22^{\mathrm{b}}$ & $58.29 \pm 0.82^{\mathrm{a}}$ & $55.31 \pm 0.88^{\mathrm{a}, \mathrm{b}}$ \\
& $\mathrm{a}^{*}$ & $-0.30 \pm 0.01^{\mathrm{e}}$ & $2.65 \pm 0.01^{\mathrm{d}}$ & $4.44 \pm 0.04^{\mathrm{c}}$ & $5.58 \pm 0.08^{\mathrm{b}}$ & $5.89 \pm 0.02^{\mathrm{a}}$ \\
& $\mathrm{b}^{*}$ & $5.16 \pm 0.03^{\mathrm{d}}$ & $7.22 \pm 0.07^{\mathrm{c}}$ & $11.45 \pm 0.35^{\mathrm{b}}$ & $12.79 \pm 0.28^{\mathrm{a}}$ & $13.28 \pm 0.26^{\mathrm{a}}$ \\
\hline
\end{tabular}

Each value is expressed as mean \pm standard deviation $(n=3)$. Different alphabet superscripts in the same row indicate significant differences $(\mathrm{p}<0.05)$ according to the Tukey test.

attributes - appearance, texture, aroma, flavor, and sweetness of the yogurts (as well as an overall rating) as rated by the 30 assessors are shown in Figure 1 using the sensory qualitative descriptive analysis (QDA). Panelists reported that the different percentages of papaya puree added to the yogurt did not differ in terms of appearance, color, texture and aroma. This is means, the addition of papaya puree to a yogurt sample does not give significant effect on the appearance and color. In regards, texture and aroma attributes, the highest score was P0 which showed that some respondents prefer to have yogurt without the addition of papaya puree. This is might due to the grainy texture of papaya puree, hence, affect the texture of the yogurt. The spider web showed that flavor and sweetness tended to increase from control as the percentage of papaya puree increases. This indicates fructose content from papaya puree contributes to the sweetness of the flavored-papaya yogurt, hence, affect the flavor. The P20 product had significantly higher scores for flavor and sweetness compared to P25. The least favorable P25 compared to P20 might due to the too-tart flavor if adding too much papaya puree into the yogurt. The "overall" scores were positively correlated with the concentration of papaya puree.

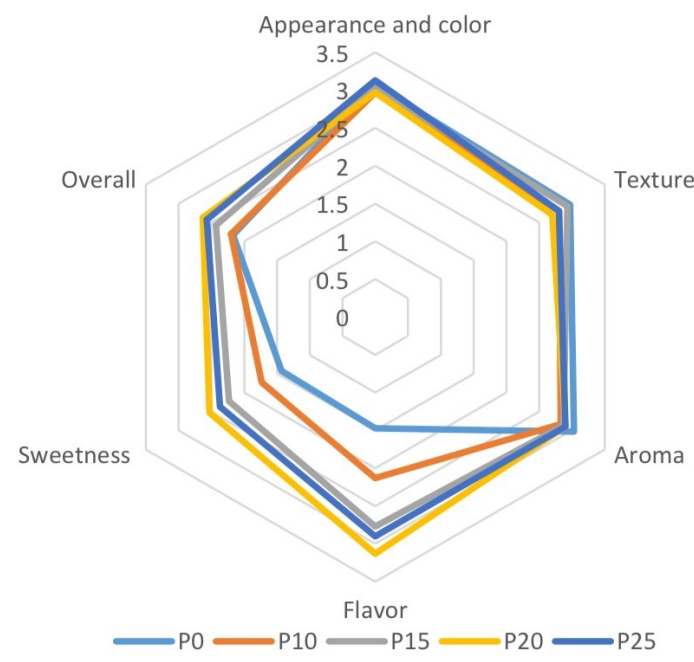

Figure 1. Spider web for quantitative descriptive analysis of P0, P10, P15, P20, and P25 samples.

\section{Conclusion}

Papaya puree clearly provided increased benefits in terms of protein content, without any significant changes to the ratings given to the appearance, texture, and aroma of the yogurts. Increasing the papaya content from $5 \%$ to $25 \%$ in the yogurts increases the protein content but decreases the fat content, and so is of nutritional benefit. Since protein accounts for the major part of papaya puree, significant differences in flavor between the flavored yogurts and the control yogurt were noticeable, with participants giving higher flavor ratings to the flavored yogurts. This study, therefore, suggests that papaya puree could be incorporated as the main protein into yogurts up to the $25 \%$ level, and the product will still be found acceptable (or even preferable) by consumers. Further studies should consider the sensory profiling, established by a trained panel to obtain a complete and detailed study of sensory characteristics of the flavored-papaya yogurt.

\section{Acknowledgment}

This research has not funded with any grants and authors declares that there is no conflict of interest regarding the publication of this paper.

\section{References}

Adetuyi, F.O., Akinadewo, L.T., Omosuli, S.V. and Lola, A. (2008). Antinutrient and antioxidant quality of waxed and unwaxed pawpaw Carica papaya fruit stored at different temperatures. African Journal of Biotechnology, 7(16), 2920-2924. https:// doi.org/10.3923/pjn.2008.658.662

Ahmed, J. (2015). Thermal Degradation Kinetics of Carotenoids and Visual Color of Papaya Puree Thermal Degradation Kinetics of Carotenoids and Visual Color of Papaya Puree, 67(7), 2692-2695. https://doi.org/10.1111/j.1365-2621.2002.tb08800.x

Amal, A.M., Eman, A.M.M. and Zidan, N.S. (2016). Fruit Flavored Yoghurt: Chemical, Functional and Rheological Properties. International Journal of Environmental and Agriculture Research, 2(5), 5766.

AOAC. (1995). Official Method of the Association of Official Chemists. Gaithersburg: AOAC International.

Barbosa, B.T., Rodrigues, J.F. and Bastos, S.C. (2017). Sensory optimization of nutritionally enriched strawberry yogurt. British Food Journal, 119(2), 301 
-310. https://doi.org/10.1108/BFJ-08-2016-0370

Bari, L., Hassan, P., Absar, N., Haque, M.E., Khuda, M.I.I.E., Pervin, M.M. and Hossain, M.I. (2006). Nutritional analysis of two local varieties of papaya (Carica papaya L.) at different maturation stages. Pakistan Journal of Biological Sciences, 9(1), 137140. https://doi.org/10.3923/pjbs.2006.137.140

BeMiller, J.N. and Low, N.H. (1998). Carbohydrate analysis. In Nielsen, S.S. (Ed.). Food Analysis, $2^{\text {nd }}$ ed. Gaithersburg: An Aspen Publication.

Boshra, V. and Tajul, A. (2013). Papaya - An Innovative Raw Material for Food and Pharmaceutical Processing Industry. Health and the Environment Journal, 4(1), 68-75.

Čakmakči, S., Četin, B., Turgut, T., Gürses, M. and Erdoğan, A. (2012). Probiotic properties, sensory qualities, and storage stability of probiotic banana yogurts. Turkish Journal of Veterinary and Animal Sciences, 36(3), 232-237. doi:10.3906/vet-1007-2

Chandan, R.C., White, C.H., Kilara, A. and Hui, Y.H. (2006). Manufacturing yogurt and fermented milks. $1^{\text {st }}$ ed. Iowa, USA: Blackwell Publishing. https:// doi.org/10.1002/9780470277812

Gomez, M., Lajolo, F. and Cordenunsi, B. (2002). Evolution of Soluble Sugars During Ripening of Papaya Fruit and its Relation to Sweet Taste, 67(1), 442-447 https://doi.org/10.1111/j.13652621.2002.tb11426.x

De La Fuente, M., Montes, F., Guerrero, G. and Juárez, M. (2003). Total and soluble contents of calcium, magnesium, phosphorus and zinc in yoghurts. Food Chemistry, 80(4), 573-578. https://doi.org/10.1016/ S0308-8146(02)00505-8

Farahat, A.M. and El-Batawy, O.I. (2013). Proteolytic Activity and Some Properties of Stirred Fruit Yoghurt Made Using Some Fruits Containing Proteolytic Enzymes. World Journal of Dairy and Food Sciences, 8(1), 38-44. https://doi.org/10.5829/ idosi.wjdfs.2013.8.1.23313

Gilliland, S.E. (1989). Acidophilus Milk Products: A Review of Potential Benefits to Consumers. Journal of Dairy Science, 72(10), 2483-2494. https:// doi.org/10.3168/jds.S0022-0302(89)79389-9

Guner, A., Ardic, M., Keles, A. and Dogruer, Y. (2007). Production of yogurt ice cream at different acidity. International Journal of Food Science and Technology, 42(8), 948-952.

Hati, S., Mandal, S. and Prajapati, J. (2013). Novel Starters for Value Added Fermented Dairy Products. Current Research in Nutrition and Food Science Journal, 1(1), 83-91. https://doi.org/10.12944/ CRNFSJ.1.1.09
Hoang, N.X., Ferng, S., Ting, C.H., Huang, W.H., Chiou, R.Y.Y. and Hsu, C.K. (2016). Optimizing the initial moromi fermentation conditions to improve the quality of soy sauce. LWT - Food Science and Technology, 74, 242-250. https://doi.org/10.1016/ j.lwt.2016.07.049

Kamruzzaman, M., Islam, M.N., Rahman, M.M., Parvin, S. and Rahman, M.F. (2002). Evaporation Rate of Moisture from Dahi (Yogurt) During Storage at Refrigerated Condition. Pakistan Journal of Nutrition, 1(5), 209-211. https://doi.org/10.3923/ pjn.2002.209.211

Klunklin, W. and Savage, G. (2018). Physicochemical Properties and Sensory Evaluation of Wheat-Purple Rice Biscuits Enriched with Green-Lipped Mussel Powder (Perna canaliculus) and Spices. Journal of Food Quality, 2018, 1-9. https:// doi.org/10.1155/2018/7697903

Kumar Dutta Roy, D. (2015). Quality Evaluation of Yogurt Supplemented with Fruit Pulp (Banana, Papaya, and Water Melon). International Journal of Nutrition and Food Sciences, 4(6), 695. https:// doi.org/10.11648/j.ijnfs.20150406.25

Kumar, P. and Mishra, H.N. (2004). Mango soy fortified set yoghurt: Effect of stabilizer addition on physicochemical, sensory and textural properties. Food Chemistry, 87(4), 501-507. https:// doi.org/10.1016/j.foodchem.2003.12.022

Lakshmipathy, R. and Sarada, N.C. (2013). Application of watermelon rind as sorbent for removal of nickel and cobalt from aqueous solution. International Journal of Mineral Processing, 122, 63-65. https:// doi.org/10.1016/j.minpro.2013.03.002

Mahmood, A. (2008). Quality of stirred buffalo milk yogurt blended with apple and banana fruits. Pakistan Journal of Agricultural Sciences, 45(2), 275-279.

Marshall, M.V. (1993). Starter cultures for milk fermentation and their characteristics. International Journal of Dairy Technology, 46(2), 49-56. https:// doi.org/10.1111/j.1471-0307.1993.tb00860.x

Medina, J.D.L.C., Gutierrez, G.V. and Garcia, H.S. (2002). PAWPAW: Post-harvest Operations. Rome: FAO

Mirzaei, E.Z., Lashani, E. and Davoodabadi, A. (2018). Antimicrobial properties of lactic acid bacteria isolated from traditional yogurt and milk against Shigella strains Antimikrobielle Eigenschaften von aus Joghurt und Milch isolierten Milchsäurebakterien gegen Shigella-Stämme. GMS Hygiene and Infection Control, 13, 4-8. doi:10.3205/ dgkh000307 
Nielsen, S.S. (2015). Food Analysis Laboratory Manual. $2^{\text {nd }}$ ed. USA: Springer. https://doi.org/10.1007/978-1 -4419-1463-7

Nwofia, G.E., Ojimelukwe, P. and Eji, C. (2012). Chemical composition of leaves, fruit pulp and seeds in some Carica papaya L. morphotypes. International Journal of Medicinal and Aromatic Plants, 2(1), 200-206.

Sapii, A.T. and Muda, F. (2005). Guidelines of Fruit Maturity and Harvesting. Malaysia: Malaysian Agriculture Research and Development Institute.

Shiby, V.K. and Mishra, H.N. (2013). Fermented Milks and Milk Products as Functional Foods-A Review. Critical Reviews in Food Science and Nutrition, 53 (5), 482-496. https:// doi.org/10.1080/10408398.2010.547398

Zuhair, R.A., Aminah, A., Sahilah, A.M. and Eqbal, D. (2013). Antioxidant activity and physicochemical properties changes of papaya (Carica papaya L. cv. Hongkong) during different ripening stage. International Food Research Journal, 20(4), 16531659. 